\title{
Dissociative symptoms reflect levels of tumor necrosis factor alpha in patients with unipolar depression
}

This article was published in the following Dove Press journal:

Neuropsychiatric Disease and Treatment

25 April 2014

Number of times this article has been viewed

\author{
Gustav Bizik' \\ Petr Bob' \\ Jiri Raboch' \\ Josef Pavlat' \\ Jana Uhrova ${ }^{2}$ \\ Hana Benakova ${ }^{2}$ \\ Tomas Zima ${ }^{2}$ \\ 'Center for Neuropsychiatric \\ Research of Traumatic Stress, \\ Department of Psychiatry and UHSL, \\ ${ }^{2}$ Department of Clinical Biochemistry \\ and Laboratory Diagnostics, \\ Ist Faculty of Medicine, Charles \\ University, Prague, Czech Republic
}

Correspondence: Gustav Bizik Department of Psychiatry, Charles University, I st Faculty of Medicine, Ke Karlovu II, 12800 Prague,

Czech Republic

Tel +420 224965 I22

Fax +420224923077

Email gustav.bizik@IfI.cuni.cz

\begin{abstract}
Recent evidence indicates that the nature of interactions between the nervous system and immune system is important in the pathogenesis of depression. Specifically, alterations in pro-inflammatory cytokines have been related to the development of several psychological and neurobiological manifestations of depressive disorder, as well as to stress exposure. A number of findings point to tumor necrosis factor alpha (TNF- $\alpha$ ) as one of the central factors in these processes. Accordingly, in the present study, we test the hypothesis that specific influences of chronic stressors related to traumatic stress and dissociation are related to alterations in TNF- $\alpha$ levels. We performed psychometric measurement of depression (Beck Depression Inventory [BDI]-II), traumatic stress symptoms (Trauma Symptom Checklist [TSC]-40), and psychological and somatoform dissociation (Dissociative Experiences Scale [DES] and Somatoform Dissociation Questionnaire [SDQ]-20, respectively), and immunochemical measure of serum TNF- $\alpha$ in 66 inpatients with unipolar depression (mean age $43.1 \pm 7.3$ years). The results show that TNF- $\alpha$ is significantly related to DES (Spearman $R=-0.42, P<0.01$ ), SDQ-20 (Spearman $R=-0.38, P<0.01$ ), and TSC-40 (Spearman $R=-0.41, P<0.01$ ), but not to BDI-II. Results of the present study suggest that TNF- $\alpha$ levels are related to dissociative symptoms and stress exposure in depressed patients.
\end{abstract}

Keywords: depression, dissociation, TNF-alpha, traumatic stress

\section{Introduction}

Advances in psychoneuroimmunological research suggest that the activation of pro-inflammatory mechanisms plays an important role in the pathophysiology of depression. ${ }^{1-4}$ Pro-inflammatory cytokines are substantially involved in this process and it has been proposed that, at least for a sub-group of depressed patients, they may represent a causal factor. ${ }^{5}$

Tumor necrosis factor alpha (TNF- $\alpha$ ), one of the prominent pro-inflammatory cytokines, has been studied largely in this context. ${ }^{5}$ It has been associated with depressive disorder in a number of cross-sectional studies, ${ }^{6-8}$ as well as one longitudinal study. ${ }^{9}$ The research, however, has extended beyond a simple association with depression; TNF- $\alpha$ has been related to different aspects of depressive symptomatology ${ }^{10,11}$ and specific emotional and cognitive disturbances. ${ }^{12}$ Moreover, TNF- $\alpha$ has been studied in relation to stress response and stressor-specific findings ${ }^{13}$ together with a moderating influence of depression ${ }^{14}$ have been identified. However, association to specific traumarelated phenomena in a depressed population, namely trauma-related and dissociative symptoms, has yet to be explored. 
Based on these data, it was postulated that serum TNF- $\alpha$ levels, measured in depressed inpatients, would be related to the assessment of both depressive symptomatology and trauma-related and dissociative symptomatology.

\section{Methods}

\section{Participants}

In order to examine the above hypothesis, assessment of basal serum TNF- $\alpha$ levels during rest conditions and psychometric measures were performed in 66 consecutive inpatients with unipolar depression on the same day. At the time of recruitment, patients were treated at the Department of Psychiatry (Charles University, Prague). The assessments were performed within 2 weeks from the admission. The patients had a diagnosis of unipolar depressive disorder (ie, patients with recurrent depression or depressive period) in relapse without posttraumatic stress disorder (PTSD) and other comorbid diagnoses confirmed according to Diagnostic and Statistical Manual of Mental Disorders (DSM) version IV criteria by clinical interview. ${ }^{15}$ In order to re-examine diagnosis and to exclude patients with PTSD or other comorbidities all patients were also screened using structured psychiatric interview The Mini-International Neuropsychiatric Interview (MINI) version 5.0.0. ${ }^{16}$ Patients' treatment at the time of recruitment was based only on antidepressant medication according to national guidelines. ${ }^{17}$ Exclusion criteria were organic illnesses involving the central nervous system, psychotic disorders, PTSD, bipolar disorder, alcohol and/or drug abuse, any form of epilepsy, and mental retardation (Raven intelligent quotient test result higher than 90 in all included patients), inflammatory, neuroendocrine, and metabolic disorders, any hormonal or antipsychotic medication, methyldopa, prednisolone and cimetidine medication, electroconvulsive therapy or repetitive transcranial magnetic stimulation, and pregnancy or lactation in women. All the patients gave written informed consent and the clinical study was approved by the ethical committee of Charles University, Prague.

\section{Psychometric measures}

For the assessment of depressive symptoms, the Beck Depression Inventory (BDI)-II, ${ }^{18}$ which is a 21 -item questionnaire for assessing depression (Cronbach's alpha 0.89, test-retest reliability after a week $=0.85)$, was used. Subjects indicated the degree of their experience of depressive symptoms on a 4-point Likert scale.

Psychic dissociative symptoms were assessed by Dissociative Experiences Scale (DES). ${ }^{19}$ DES represents a 28 item self-reported questionnaire examining main dissociative phenomena such as absorption, amnesia, depersonalization, derealization, reality distortion, and others. Subjects indicate a degree of their experience on the continuum from $0 \%$ to $100 \%$. In the present study, we used the Czech version of the DES that, similar to the original English version, displays high reliability and internal consistency (Cronbach's alpha 0.92 , test-retest reliability after a week $=0.91$ ).

Somatoform dissociative symptoms were assessed using the 20-item self-reported Somatoform Dissociation Questionnaire (SDQ-20). ${ }^{20}$ Somatoform dissociative symptoms represent alterations in sensations of pain (analgesia, kinesthetic anesthesia), alterations of perception, loss of motor control, gastrointestinal symptoms, etc. Subjects indicate the degree of their experience on a 5-point Likert scale. We used the Czech version of the SDQ-20 that displays high reliability and internal consistency (Cronbach's alpha 0.91, test-retest reliability after a week $=0.90)$.

For investigation of traumatic symptoms, the Trauma Symptom Checklist (TSC)-40 ${ }^{21}$ was used. TSC-40 is a selfreported 40-item questionnaire done on a 4-point Likert scale. TSC-40 evaluates symptomatology in adults associated with childhood or adult traumatic experiences and measures aspects of posttraumatic stress and other symptom clusters found in some traumatized individuals. The Czech version of the TSC-40 has high reliability and internal consistency (Cronbach's alpha 0.91, test-retest reliability after a week $=0.88)$.

\section{Immunochemical measures}

For biochemical assessment, blood samples of $5 \mathrm{~mL}$ volumes were collected in rest conditions according to common procedures between 7:30 am and 8:00 am in the laboratory of the psychiatry department. The blood samples were carefully transferred (about 10 minutes) in an icebox at $4^{\circ} \mathrm{C}$ to the Central Laboratories of the Institute of Medical Biochemistry and Laboratory Diagnostics, 1st Faculty of Medicine Charles University and General University Hospital in Prague where they were immediately centrifuged $\left(4^{\circ} \mathrm{C}, 3,000 \mathrm{rpm}, 10\right.$ minutes $)$, pipetted into vials $2 \times 0.5 \mathrm{~mL}$ each, and stored at $-20^{\circ} \mathrm{C}$ until the time of analysis. TNF- $\alpha$ serum levels were measured using a commercial immunoradiometric assay (IRMA) provided by DRG Instruments GmbH (Marburg, Germany). Principles of the TNF- $\alpha$ IRMA assay were based on coated-tube separation. The capture antibodies were attached to the lower and inner surface of the plastic tube. Standards or samples added to the tubes at first showed low affinity for antibodies. The signal antibody labeled with ${ }^{125}$ I triggered the immunological reaction. After washing, the remaining radioactivity bound to the tube reflected the antigen concentration. Precision of the TNF- $\alpha$ IRMA corresponded to intra-assay coefficients 
of variation $<7.0 \%$. Sensitivity of the TNF- $\alpha$ concentration corresponding to the mean counts per minute +2 standard deviations (SD) was $5 \mathrm{pg} / \mathrm{mL}$.

\section{Statistical methods}

Statistical description of the studied population included means and SD. In order to assess the relationship between TNF- $\alpha$ levels and psychometric measures, the Spearman rank correlation coefficient were determined. The Spearman rank correlation coefficient represents a robust nonparametric measure of correlation, resistant to the presence of outliers. ${ }^{22}$

All the methods of statistical evaluation were performed using the software package Statistica version 6 (StatSoft Inc., Tulsa, OH, USA). The statistical significance was presumed at a $P$-value $<0.05$.

\section{Results}

Table 1 presents the demographic and biometric characteristics of the studied population. Table 2 summarizes the drug treatment in the studied population.

The results indicate that TNF- $\alpha$ is significantly correlated to DES (Spearman $R=-0.42, P<0.01$ ) (Figure 1), SDQ-20 (Spearman $R=-0.38, P<0.01$ ) (Figure 2), and TSC-40 (Spearman $R=-0.41, P<0.01$ ), but not to BDI-II (Table 3). These correlations show that TNF- $\alpha$ exhibits a significant relationship with psychological and somatoform dissociation and the symptoms related to traumatic stress. Other statistically significant correlations were also found between psychometric measures of depression, traumatic stress, and dissociation (Table 3).

Statistical comparison between men and women did not show significant differences in TNF- $\alpha$ or psychometric measures. No significant correlation was found between BMI and age and TNF- $\alpha$ and psychometric parameters.

\section{Discussion}

In accordance with our hypothesis, results of the present study confirm a statistically significant relationship between

Table I Demographic and biometric characteristics of the studied population

\begin{tabular}{ll}
\hline & Depressed patients $(\mathbf{n}=66)$ \\
\hline Male:female & $21: 45$ \\
Age in years (mean \pm SD; min, max) & $43.1( \pm 7.3 ; 18,60)$ \\
Education & \\
$\quad$ Elementary & 5 \\
Higher & 50 \\
University & II \\
BMI (mean \pm SD; min, max) & $25.4( \pm 5.13 ; 18,40.6)$ \\
\hline
\end{tabular}

Abbreviations: BMI, body mass index; max, maximum; min, minimum; SD, standard deviation.
Table 2 Drug treatment in the studied population

\begin{tabular}{|c|c|c|c|}
\hline & $\begin{array}{l}\text { Number } \\
\text { of patients }\end{array}$ & $\begin{array}{l}\text { Percentage } \\
\text { of patients } \\
(\%)\end{array}$ & $\begin{array}{l}\text { Dosage in mg } \\
(m e a n \pm S D ; \\
\text { min, } \max )\end{array}$ \\
\hline Unmedicated & 3 & 4.5 & \\
\hline \multicolumn{4}{|l|}{ Medicated } \\
\hline $\begin{array}{l}\text { One } \\
\text { antidepressant }\end{array}$ & 48 & 72.7 & \\
\hline $\begin{array}{l}\text { Two } \\
\text { antidepressants }\end{array}$ & 15 & 22.7 & \\
\hline \multicolumn{4}{|c|}{ Antidepressant treatment } \\
\hline Amitriptyline & 2 & 3 & 140 \\
\hline Dibenzepin & 3 & 4.5 & $500 \pm 242.5 ; 240,720$ \\
\hline Trazodone & 6 & 9.1 & $227 \pm 160.8 ; 50,300$ \\
\hline Moclobemide & I & 1.5 & 900 \\
\hline Fluvoxamine & I & 1.5 & 100 \\
\hline Fluoxetine & I & 1.5 & 40 \\
\hline Sertraline & 16 & 24.2 & $109 \pm 55.4 ; 25,200$ \\
\hline Citalopram & 14 & 21.2 & $4 I \pm 10.7 ; 20,60$ \\
\hline Paroxetine & I & 1.5 & 60 \\
\hline Escitalopram & 6 & 9.1 & $19 \pm 8.4 ; 10,30$ \\
\hline Venlafaxine & 7 & 10.6 & $184 \pm 71.9 ; 150,300$ \\
\hline Mirtazapine & 17 & 25.8 & $43 \pm 9 ; 30,60$ \\
\hline Milnacipran & 3 & 4.5 & $167 \pm 55.7 ; 100,200$ \\
\hline
\end{tabular}

Abbreviations: max, maximum; min, minimum; SD, standard deviation.

TNF- $\alpha$ levels and the symptoms linked to chronic stressful experiences in depressed patients. However, the fact that the correlation is negative, is surprising and seems to be in contrast to both the theoretical framework and our previous research focused on interleukin (IL)-6, another pro-inflammatory cytokine. Moreover, unexpectedly, no significant relationship is revealed between TNF- $\alpha$ and depressive symptoms.

In order to understand the observed relationship between TNF- $\alpha$ and dissociative symptoms, studies on the hypothalamo-pituitary axis (HPA) activation in depression appear relevant. Importantly, a negative correlation was found between cortisol and somatoform dissociation in a population of depressed patients. ${ }^{23}$ On the other hand, TNF- $\alpha$ was reported to increase the HPA activity in depression. ${ }^{5}$

Table 3 Spearman correlations of TNF- $\alpha$ and results of psychometric measures

\begin{tabular}{lllll}
\hline & TNF- $\alpha$ & BDI-II & TSC-40 & DES \\
\hline BDI-II & -0.04 & - & - & - \\
TSC-40 & $-0.4 I^{* *}$ & $0.43^{* *}$ & - & - \\
DES & $-0.42^{* *}$ & $0.29 *$ & $0.60^{* *}$ & - \\
SDQ-20 & $-0.38^{* *}$ & $0.34^{* *}$ & $0.68^{* *}$ & $0.69 * *$ \\
\hline
\end{tabular}

Notes: $* P<0.05 ; * * P<0.01$.

Abbreviations: BDI, Beck Depression Inventory; DES, Dissociative Experiences Scale; SDQ, Somatoform Dissociation Questionnaire; TNF- $\alpha$, tumor necrosis factor alpha; TSC, Trauma Symptom Checklist. 


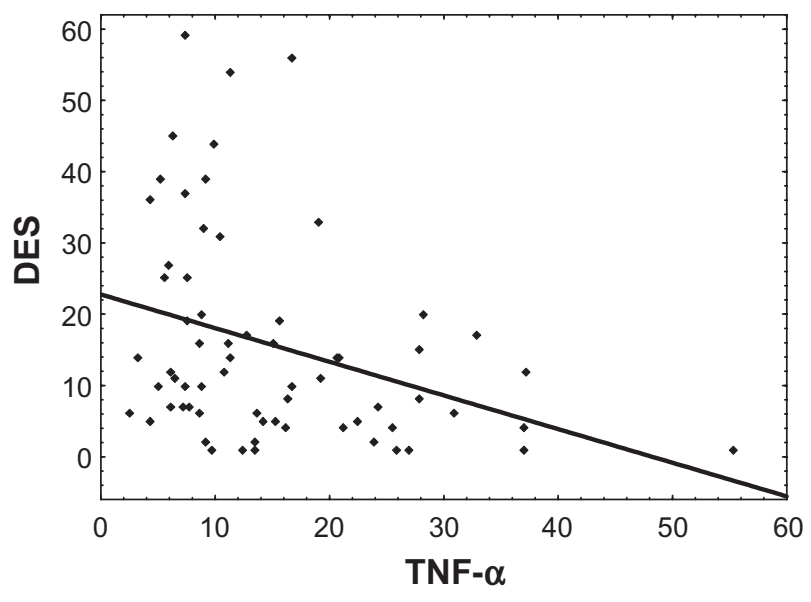

Figure I Dependency graph of TNF- $\alpha(\mathrm{pg} / \mathrm{mL})$ and DES (Spearman $R=-0.36$, $P<0.0$ I).

Abbreviations: DES, Dissociative Experiences Scale; TNF- $\alpha$, tumor necrosis factor alpha.

The present finding is in line with these results pointing to the fact that somatoform dissociation may moderate the interplay between TNF- $\alpha$ and HPA activity in depression. Noteworthy, our previous work reported a positive correlation between IL-6 and somatoform dissociation. ${ }^{24}$ Interestingly, taken together, both findings are consistent with the reported inhibition between TNF- $\alpha$ by IL- $6^{25}$ and they indicate that a complex interaction between the two pro-inflammatory cytokines and their neurobiological effect may exist.

Similarly, the negative correlation between TNF- $\alpha$ and trauma-related symptoms is in an apparent contradiction with the theoretical framework. Notably, acute stress conditions are associated with an increase in TNF- $\alpha$ in depressed patients. ${ }^{26}$ Nevertheless, when focusing specifically on

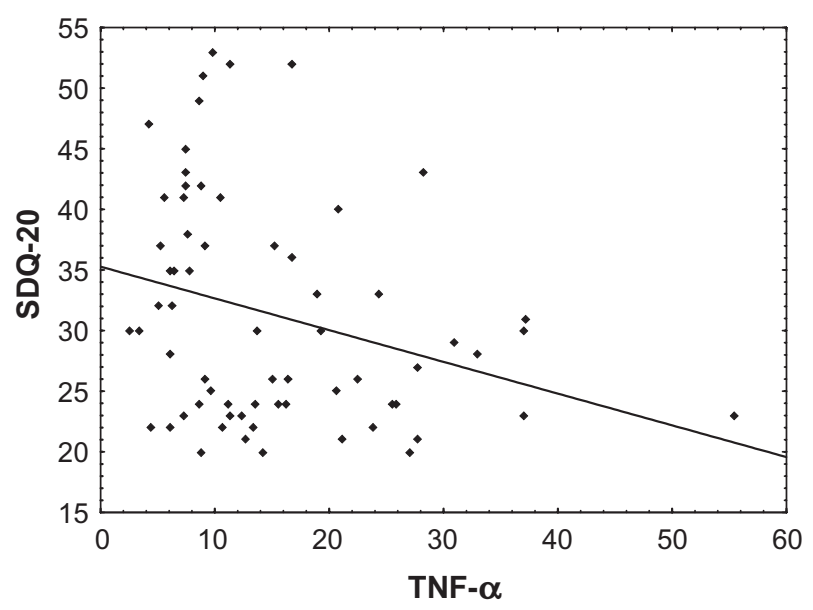

Figure 2 Dependency graph of TNF- $\alpha(\mathrm{pg} / \mathrm{mL}$ ) and SDQ-20 (Spearman $R=-0.30$, $P<0.05)$.

Abbreviations: SDQ, Somatoform Dissociation Questionnaire; TNF- $\alpha$, tumor necrosis factor alpha. chronic stress conditions, the result corresponds to the work by Bartolomucci et $\mathrm{al}^{27}$ who observed that chronic psychosocial stress down-regulated TNF- $\alpha$ messenger ribonucleic acid (mRNA) levels in the striatum and hippocampus.

Finally, as stated previously, finding no relevant association between TNF- $\alpha$ and depressive symptoms was unexpected. Mean serum TNF- $\alpha$ level for the whole group $(25.4 \mathrm{pg} / \mathrm{mL} \pm 5.1 \mathrm{SD})$ appears higher than the TNF- $\alpha$ serum values reported in healthy volunteers $(1-10 \mathrm{pg} / \mathrm{mL}){ }^{8}$ Nevertheless, TNF- $\alpha$ assessment was not performed in healthy controls in our study and only a single self-reported test was used to assess the depressive symptoms (BDI-II). Therefore, it is not possible to decide if the lack of correlation between TNF- $\alpha$ and depressive symptoms is due to low TNF- $\alpha$ levels in the depressed group, a low sensitivity of psychometric instrument, or another reason.

The present study has several limitations. First, since the scope of the study is to describe the nature of the relationship between TFN- $\alpha$ and specific psychometric characteristics in depressive disorders, no healthy or other control group was included in the analysis. The interpretation of the findings is therefore limited to this clinical condition. Second, the main focus on trauma-related psychopathology determined largely the choice of psychometric test, preferring reliable and widely used self-reported tests such as DES, SDQ-20, and TSC-40. As a result, the findings may be set in the context with the large body of research performed using these instruments while further interpretation must be done with precaution, taking into account the limitation imposed by the self-reported nature of the testing. This precaution is relevant even more for the interpretation of results related to depressive symptoms, as already mentioned. Third, while patient recruitment led to a quite naturalist clinical cohort, the characteristics of the studied group (inpatients, heterogeneous antidepressant treatment) limit the findings. In particular, the effect of antidepressant treatment may vary considerably between different substances and therapeutic regimens. ${ }^{28-30} \mathrm{~A}$ larger clinical group and a longitudinal study design is needed to address this issue. Lastly, the study is limited to only one of a large group of pro-inflammatory cytokines. In order to have a complex insight into the role of immune processes in emotional regulation and the development of affective disorders, other pro- and anti-inflammatory cytokines together with stress axis activity have to be explored..$^{2,13}$

Altogether, TNF- $\alpha$ has been intensively studied as one of the prominent candidates in the cytokine model of depression. The role of TNF- $\alpha$ within depressive disorder seems, however, rather complex; specific emotional and stress system 
regulations may play an important role. The findings of the present study reveal a tiny piece in this puzzle, encouraging further efforts to describe in more detail the interplay of TNF- $\alpha$ regulations and chronic stress and dissociative processes in the development and clinical manifestation of depression.

\section{Acknowledgments}

The study was supported by the grant GACR P407/12/1957, project MSM0021620849 provided by the Czech Ministry of education and the project "CEITEC - Central European Institute of Technology" (CZ.1.05/1.1.00/02.0068) from the European Regional Development Fund.

\section{Disclosure}

The authors report no conflicts of interest in this work.

\section{References}

1. Wichers M, Maes M. The psychoneuroimmuno-pathophysiology of cytokine-induced depression in humans. Int J Neuropsychopharmacol. 2002;5(4):375-388.

2. Schiepers OJ, Wichers MC, Maes M. Cytokines and major depression. Prog Neuropsychopharmacol Biol Psychiatry. 2005;29(2): 201-217.

3. Raison CL, Capuron L, Miller AH. Cytokines sing the blues: inflammation and the pathogenesis of depression. Trends Immunol. 2006;27(1):24-31.

4. Blume J, Douglas SD, Evans DL. Immune suppression and immune activation in depression. Brain Behav Immun. 2011;25(2):221-229.

5. Himmerich H, Fulda S, Linseisen J, et al. Depression, comorbidities and the TNF-alpha system. Eur Psychiatry. 2008;23(6):421-429.

6. Zorrilla EP, Luborsky L, McKay JR, et al. The relationship of depression and stressors to immunological assays: a meta-analytic review. Brain Behav Immun. 2001;15(3):199-226.

7. Howren MB, Lamkin DM, Suls J. Associations of depression with C-reactive protein, IL-1, and IL-6: a meta-analysis. Psychosom Med. 2009;71(2):171-186.

8. Dowlati Y, Herrmann N, Swardfager W, et al. A meta-analysis of cytokines in major depression. Biol Psychiatry. 2010;67(5):446-457.

9. van Zuiden M, Heijnen CJ, van de Schoot R, et al. Cytokine production by leukocytes of military personnel with depressive symptoms after deployment to a combat-zone: a prospective, longitudinal study. PLoS ONE. 2011;6(12):e29142.

10. Hauser P, Khosla J, Aurora H, et al. A prospective study of the incidence and open-label treatment of interferon-induced major depressive disorder in patients with hepatitis C. Mol Psychiatry. 2002;7(9): 942-947.

11. Kraus MR, Schäfer A, Faller H, Csef H, Scheurlen M. Psychiatric symptoms in patients with chronic hepatitis $\mathrm{C}$ receiving interferon alfa-2b therapy. J Clin Psychiatry. 2003;64(6):708-714.
12. Reichenberg A, Yirmiya R, Schuld A, et al. Cytokine-associated emotional and cognitive disturbances in humans. Arch Gen Psychiatry. 2001;58(5):445-452.

13. García-Bueno B, Caso JR, Leza JC. Stress as a neuroinflammatory condition in brain: damaging and protective mechanisms. Neurosci Biobehav Rev. 2008;32(6):1136-1151.

14. Weinstein AA, Deuster PA, Francis JL, Bonsall RW, Tracy RP, Kop WJ. Neurohormonal and inflammatory hyper-responsiveness to acute mental stress in depression. Biol Psychol. 2010;84(2):228-234.

15. American Psychiatric Association. DSM IV, Diagnostic and Statistical Manual of Mental Disorders. Washington: American Psychiatric Association; 1994

16. Sheehan DV, Lecrubier Y, Sheehan KH, et al. The Mini-International Neuropsychiatric Interview (M.I.N.I.): the development and validation of a structured diagnostic psychiatric interview for DSM-IV and ICD-10. J Clin Psychiatry. 1998;59 Suppl 20:22-33;quiz 34.

17. Raboch J, Anders M, Prasko J, Hellerova P. Doporučené postupy psychiatrické péče II [Recommended procedures in psychiatric care] Praha: Infopharm; 2006. Czech.

18. Beck AT, Steer RA, Brown GK. Manual for Beck Depression Inventory - II. San Antonio: Psychological Corporation; 1996.

19. Bernstein EM, Putnam FW. Development, reliability, and validity of a dissociation scale. J Nerv Ment Dis. 1986;174(12):727-735.

20. Nijenhuis ER, Spinhoven P, Van Dyck R, Van der Hart O, Vanderlinden J. The development and psychometric characteristics of the Somatoform Dissociation Questionnaire (SDQ-20). J Nerv Ment Dis. 1996;184(11):688-694.

21. Briere J. Psychometric review of the Trauma Symptom Checklist-40. In: Stamm BH, editor. Measurement of Stress, Trauma, and Adaptation. Lutherville: Sidran Press; 1996: pages 381-383.

22. Abdullah MB. On a robust correlation coefficient. Statistician. 1990;39(4):455-460.

23. Bob P, Freybergh PF, Jasova D, et al. Depression, cortisol and somatoform dissociative symptoms. Neuro Endocrinol Lett. 2008;29(2): 235-239.

24. Bob P, Raboch J, Maes M, et al. Depression, traumatic stress and interleukin-6. J Affect Disord. 2010;120(1-3):231-234.

25. Hirano T, Akira S, Taga T, Kishimoto T. Biological and clinical aspects of interleukin 6. Immunol Today. 1990;11(12):443-449.

26. Pepys MB, Hirschfield GM. C-reactive protein: a critical update. J Clin Invest. 2003;111(12):1805-1812.

27. Bartolomucci A, Palanza P, Parmigiani S, et al. Chronic psychosocial stress down-regulates central cytokines mRNA. Brain Res Bull. 2003;62(3):173-178.

28. Kraus T, Haack M, Schuld A, Hinze-Selch D, Koethe D, Pollmächer T. Body weight, the tumor necrosis factor system, and leptin production during treatment with mirtazapine or venlafaxine. Pharmacopsychiatry. 2002;35(6):220-225.

29. Brustolim D, Ribeiro-dos-Santos R, Kast RE, Altschuler EL, Soares MB A new chapter opens in anti-inflammatory treatments: the antidepressant bupropion lowers production of tumor necrosis factor-alpha and interferon-gamma in mice. Int Immunopharmacol. 2006;6(6):903-907.

30. Janssen DG, Caniato RN, Verster JC, Baune BT. A psychoneuroimmunological review on cytokines involved in antidepressant treatment response. Hum Psychopharmacol. 2010;25(3):201-215.
Neuropsychiatric Disease and Treatment

\section{Publish your work in this journal}

Neuropsychiatric Disease and Treatment is an international, peerreviewed journal of clinical therapeutics and pharmacology focusing on concise rapid reporting of clinical or pre-clinical studies on a range of neuropsychiatric and neurological disorders. This journa is indexed on PubMed Central, the 'PsycINFO' database and CAS

\section{Dovepress}

The manuscript management system is completely online and includes a very quick and fair peer-review system, which is all easy to use. Visit http://www.dovepress.com/testimonials.php to read real quotes from published authors. 